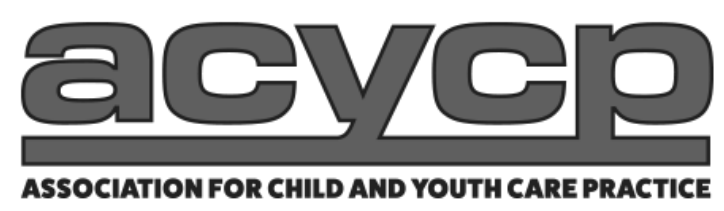

\title{
Erratum to Mann-Feder, V. (2020). Experiential Teaching and Learning in Child and Youth Care Work: An Integrative Approach to Graduate Education. Journal of Child and Youth Care Work, 26. https://doi.org/10.5195/jcycw.2020.5
}

\section{Dale Curry}

In the article "Experiential teaching and learning in Child and Youth Care Work: An integrative approach to graduate education" (DOI 10.5195/jcycw.2020.5), co-authors were omitted. The authors are Varda R. Mann-Feder, Elizabeth Fast, Stephanie Hovington, and Patti Ranahan. The online version has been updated to reflect this change. 